\title{
Underspecification, Parsing Mismatches and Routinisation: The Historical Development of the Clitic Systems of Greek Dialects
}

\section{Stergios Chatzikyriakidis ${ }^{1}$}

Published online: 20 August 2020

(c) The Author(s) 2020

\begin{abstract}
In this paper, the historical development of the clitic systems of Standard Modern, Cypriot and Pontic Greek is discussed. These three varieties not only present the whole range of variation one can find across clitic systems in Greek but, furthermore, derive from a common linguistic ancestor, i.e. Koine Greek. This paper argues that the transition from Koine Greek to the Medieval varieties and from the Medieval varieties to the respective modern ones can be explained by making the assumption that routinisation (in the sense of Pickering and Garrod in Behav Brain Sci 27:169226,2004 ) and parsing/hearer assymetries are two important factors behind syntactic change. The claim is that the transition from Koine to the Medieval Greek varieties involves the emergence of a clitic system with encoded syntactic constraints out of a freer one, where clitic positioning was regulated by pragmatic preferences rather than syntactic constraints. Then, the transition to the modern varieties from the respective medieval ones is explained, at least partly, on the assumption that production/parsing mismatches are capable of triggering syntactic change. This last assumption combined with: (a) the tendency to obtain more generalised parsing triggers for parsing the individual clitics and (b) the fact that the Medieval varieties in question differ in minimal but crucial ways, provides us an explanation for the transition to the modern varieties.
\end{abstract}

Keywords Dynamic Syntax · Diachronic change · Routinization · Parsing/production assymetries

Stergios Chatzikyriakidis stergios.chatzikyriakidis@gu.se

1 Centre for Linguistic Theory and Studies in Probability, Department of Philosophy, Linguistics and Theory of Science, University of Gothenburg, Gothenburg, Sweden 


\section{Introduction}

Looking at the clitic systems of Modern Greek (MG) varieties, one can distinguish three types of clitic systems, at least as regards their positioning restrictions. The first type of clitic system is exhibited by the dominant Standard Modern Greek (SMG) variety and the Grico dialect, with its Romance counterparts being Standard Italian and Spanish. ${ }^{1,2}$ In this type of systems, clitic positioning can be described as proclitic in non-imperative and enclitic in imperative and gerund environments. ${ }^{3}$ This type of system is exemplified below with data from SMG:
Ton
a $\gamma$ apá

him.CL- ACC love.3SG

'S/He/It loves him.' [SMG]

(2) *A $\gamma$ apá ton

love.3SG him.CL- ACC

'S/He/It loves him.' [SMG]

(3)

$\Gamma$ ráfe to

write.IMP- 2SG it.CL- ACC

'Write it!' [SMG]

(4)

$*$ To $\quad \gamma$ ráfe
it.CL- ACC write.IMP- $2 S G$
'Write it!' [SMG]

(5) $\Gamma$ ráfodas to...

write.GER it.CL- ACC

'By writing it...' [SMG]

(6) *To $\quad \gamma$ ráfodas $\ldots$

it.CL- ACC write.GER

'By writing it...' [SMG]

The second type of system is the one exhibited by varieties like Cypriot Greek in the case of Greek (CG) (Revithiadou and Spyropoulos 2008; Chatzikyriakidis 2012), while its Romance counterparts are languages like European Portuguese (Crysmann 2001; Luis et al. 2004), Asturian Spanish (Crysmann 2001; Lu1s et al. 2004) Medieval Spanish (Bouzouita 2008) and Medieval Greek (Pappas 2004b; Soltic 2013). In these varieties, clitic positioning is in general enclitic (7) unless a number of proclitic triggers appear at the left periphery. These elements include tense/aspect and negation markers (8)-(11), subordinating conjunctions (12)-(13) as well as fronted arguments and adverbs (14)-(16). We exemplify this type of system with examples from CG: ${ }^{4}$

\footnotetext{
${ }^{1}$ See Katsoyannou (1995) for the Calabrian variety and Chatzikyriakidis (2009a, b, 2010a) for the clitic system of the Grecia Salentina variety. The standard reference grammar for both varieties is Rohlfs (1977).

2 The comparison to Romance varieties is important, since the main bulk of the analysis will draw inspiration from the work of Bouzouita (2008) and her study of the transition from Medieval to Modern Spanish.

3 The terms proclitic and enclitic refer to syntactic positioning rather than the phonological clisis of the pronoun.

${ }^{4}$ Note that examples (14)-(16) can appear with enclisis as well. See Pappas $(2008,2012)$ and Chatzikyriakidis (2012) for the relevant data. For a detailed assessment of these variation environments using a 
(7) Kseri tin

know.3SG her.CL- ACC

'S/He knows her.'

(8) $P \cos$ ton íse (*ton)?

who.NOM him.CL- ACC saw.3SG him.CL- ACC

'Who saw him?'

(9) En ton ikséro (*ton).

NEG him.CL- ACC know.1SG him.CL- ACC

'I do not know him.'

(10) $\Theta$ élo na ton $\delta$ (*ton).

want.1SG SUBJ him.CL- ACC see.1SG him.CL- ACC

'I want to see him.'

(11) Ennaton $\quad \delta$ o (*ton) (a)pópse .

FUT him.CL- ACC see.1sG him.CL- ACC tonight

'I'm going to see him tonight.'

(12) Mólis ton í $\mathrm{a}$ (*ton),...

as-soon-as him.CL- ACC saw.1SG him.CL- ACC

'As soon as I saw him,...'

(13) An ton $\quad$ íte $\quad(*$ ton $), \ldots$

if him.CL- ACC saw.2PL him.CL- ACC

'If you see him...'

(14) I MARIA ton ikséri ói i Ioanna

the.NOM Mary.NOM him.CL- ACC know.3SG not the.NOM Ioana.NOM

'Mary knows him, not Ioanna.'

(15) XTES ton $1 \delta \mathrm{a}$

yesterday him.CL- ACC saw.1SG

'It was yesterday that I saw him.'

ECÍ to $\quad \theta$ élo

there it.CL- ACC want.1SG

'I want it there.'

The third type of positioning system, which does not have a Romance counterpart, is the system exhibited by Pontic Greek (PG). In this dialect, clitic positioning is always postverbal no matter the form of the verb or the presence of any type of element in the left periphery (Chatzikyriakidis 2010b):

\footnotetext{
Magnitude Estimation Study (MET), please check Pappas (2014). There is also work on the sociolinguistics of clitic positioning in CG. There, a number of sociolinguistic factors are shown to be responsible for variation environments, e.g. diglossia. However, whatever the effect of these factors is in speaker judgments, one will have to explain the fact that speakers readily accept variation with specific elements in judgment elicitation tasks (e.g. complementiser oti "that"), while they do not so with other elements (e.g. complementiser $p u$ "that"). We will not get into a discussion of these factors here, but the reader has to keep in mind that they are also at play with respect to clitic positioning. For discussions along these lines, see Tsiplakou (2017) and Grohmann et al. (2017).
} 
(17) (*Aton) Eksér aton

know.1SG him.CL

'I know him.'

(18) $\quad(* \mathrm{Me}) \quad \Delta$ ós me a(v)úto to vivlío

give.2SG- IMP me.CL this the book

'Give me this book.'

(19) $\mathrm{Ci}$ (*aton) ksér aton

NEG know.1SG him.ACC

'I do not know him.'

(20) Píos (*aton) edók aton?

who him.CL hit.1SG him.CL

'Who hit him?'

It is a rather uncontroversial assumption in Greek linguistics that all the MG dialects, as well as the dominant SMG variety, with the exception of Tsakonian, ultimately derive from Koine Greek (KG) (Hatzidakis 1897; Horrocks 1997; Ralli 2006). ${ }^{5}$ In this sense, our point of departure in explaining the clitic systems of the three varieties under consideration will be KG. If we look at the descriptions of the KG clitic system (Janse 1993; Taylor 2002) one gets the idea that the KG system is quite similar to the one we find in languages of the second type (CG), given that enclisis is in general the case but proclisis can arise in contexts where a fronted element (21), (22), a function word (23), (24), or a subordinating conjunction is present (examples from Janse (1993)):

Egō se edoksasa epi tēs gēs

I you.CL- ACC glorify in the earth

'I glorified you in the earth.'

Oudeis se katekrinen

none you.CL- ACC blamed

'No one blamed you.'

Tis mu epsato
who.NOM me.CL- GEN touched
'Who touched me?'
Mē mi kopus parehe
NEG me.CL- DAT trouble give
'Do not give me trouble.'

However the difference between the system exhibited by $\mathrm{KG}$ and systems like $\mathrm{CG}$ is that restrictions on clitic positioning are not yet strict and thus variation (both preverbal and postverbal positioning being possible) is robust in almost all environments. Clear examples of this variation are found in Oxyrynchus Papyri. The data presented by Pappas (2004b) clearly exemplify the situation described:

\footnotetext{
$\overline{5}$ But see Sitaridou and Schreiber (2015) for an alternative view. 
(25) Clitic positioning in the Oxyrynchus Papyri (vols. 1-56, adapted from Pappas 2006:323) ${ }^{6}$

\begin{tabular}{|r|r|r|}
\hline Environment & Preverbal & Postverbal \\
\hline Clause initial & 4 & 231 \\
\hline Infinitival complement & 12 & 0 \\
\hline Adverbs & 34 & 14 \\
\hline NP-object & 21 & 15 \\
\hline NP-Subject & 10 & 13 \\
\hline PP & 13 & 37 \\
\hline Complementisers & 17 & 37 \\
\hline Wh-expressions & 18 & 16 \\
\hline
\end{tabular}

What is rather interesting in the above table is that variation, with the exception of infinitives, is found in all environments, even in clause initial position, a clear violation of the first position restriction, also known as the Tobler-Mussafia law. ${ }^{7}$ It comes thus as no surprise that all the analyses that try to deal with clitic positioning in KG (Janse 1993; Taylor 2002) are unable to deal with this kind of situation given that the generalisations or syntactic restrictions they pose are far too strong and as such preclude one of the variation environments. For example, the analysis presented in Taylor (2002) crucially relies on the following three assumptions: (a) KG clitics are enclitics, (b) they attach to the left edge of a VP, and (c) Prosodic Inversion (PI) plus $\Phi$ restructuring are operative. ${ }^{8}$ As Pappas (2004b) notes, such an account would predict complementisers, negative markers and Wh-expressions to be always associated with preverbal positioning, since these will belong to the phonological phrase of the verb. Hence, the clitic does not undergo PI because a host will be available to its left. However, variation in all these environments is vast, with enclisis being an option in these cases as well. The same considerations apply to analyses like Condoravdi and Kiparsky (2002), as Pappas (2004b) claims. I will not go through the exact details of how these analyses fail to capture the KG clitic positioning system but the interested reader is directed to Pappas (2004b) and Chatzikyriakidis (2010a) for a full-blown review of the problems associated with all these accounts.

In what follows, I will argue that these problems immediately disappear if we assume that the peculiar positioning restrictions of the $\mathrm{KG}$ clitic system are due to the fact that these syntactic restrictions are not in fact there. The assumption will be that the KG clitic positioning system is governed by pragmatic preferences rather than syntactic restrictions. This last assumption combined with the claim that routinisation and parsing/hearer assymetries drive syntactic change will explain the transition from $\mathrm{KG}$ to the medieval varieties.

\footnotetext{
${ }^{6}$ Clause initial includes both root and non-root clauses, no doubling cases are found in the NP-object category and both adverbial and argumental PPs are included in the PP category (mostly adverbial though).

7 The rule states that clitics appear postverbally only in case preverbal placement would position them in sentence initial position. This has been first mentioned in Tobler (1912) and Mussafia (1886).

$8 \Phi$ restructuring refers to Phonological Phrase restructuring as this was defined by Vogel and Nespor (1997).
} 
The paper is structured as follows: Sect. 2 gives a brief to the basic ideas behind Dynamic Syntax (DS) (Kempson et al. 2001; Cann et al. 2005). Priority is given to ideas and parts of the formalism that are relevant for the current paper. In Sect. 3, we look at the clitic system of $\mathrm{KG}$, defending a view where the $\mathrm{KG}$ clitic system can be better explained as a pragmatically governed system instead of a system with hardcoded syntactic restrictions. In chapters 3 and 4, the transition from KG to the Medieval dialects and from the Medieval dialects to the modern ones respectively are discussed, claiming that a nature explanation can be provided within the DS framework, once the assumption that routinisation and parser/hearer mismatches play an important role in syntactic change.

\section{A Brief Introduction to DS}

\subsection{Basic Assumptions}

The Dynamic Syntax (DS) framework (Kempson et al. 2001; Cann et al. 2005) is a dynamic, processing oriented framework for natural language syntax. According to one of the basic assumptions behind DS, natural language syntax is taken to be the progressive accumulation of transparent semantic representations with the upper goal being the construction of a logical propositional formula (a formula of type $t$ ). This process is driven by means of monotonic tree growth, representing the attempt to model the way information is processed in a time-linear, incremental, word-to-word manner. DS is a goal driven framework, in which a number of requirements get progressively satisfied (requirements are denoted by the question mark?). The example below shows the starting point and the end result of parsing the SMG sentence $o$ Giorgos agapai ti Maria 'George loves Mary':

$\stackrel{\text { Starting point }}{\longmapsto}$

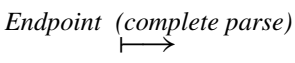

$? T y(t)$

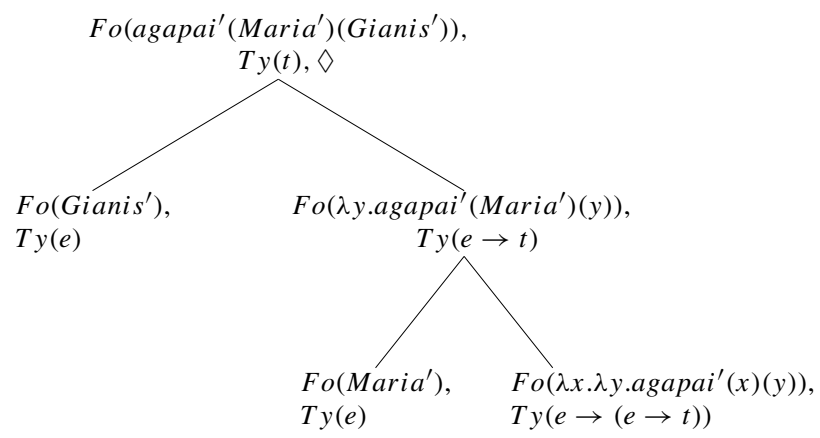


As already said, the end goal is to arrive at a tree structure with no outstanding requirements. A sentence/utterance is then said to be grammatical iff there exists a sequence of tree-updates that leads to a tree structure where all nodes have type and formula values and no outstanding requirements exist. This is true in the above example, where in the tree structure on the right, all nodes have formula (Fo) and type (Ty) values. ${ }^{9}$ Formula and type values combine via functional application and modus ponens respectively. The $\diamond$ sign, called the pointer, is a tracking device, tracking the place in the tree where the parsing process is at a given point. ${ }^{10}$ The whole system is underpinned by the Logic of Finite Trees (Blackburn and Meyer-Viol 1994), an expressive modal language to talk about trees. LOFT uses two basic arrow relations $\downarrow$ and $\uparrow$, corresponding to the daughter and mother relation respectively. Left nodes are addressed as 0 nodes, whereas right nodes as 1 nodes. By convention, nodes on the left correspond to the argument nodes, i.e. the nodes in which the arguments will be represented, whereas the 1 nodes correspond to the functor nodes, i.e. the nodes in which all the various types of predicates will be represented. The rootnode, defined as the sole node that does not have a mother node, is given the treenode address 0 . The example below illustrates the flexibility of LOFT by showing a binary tree where different nodes are addressed from the perspective of other nodes using treenode relations:

The LOFT treenode relations in action

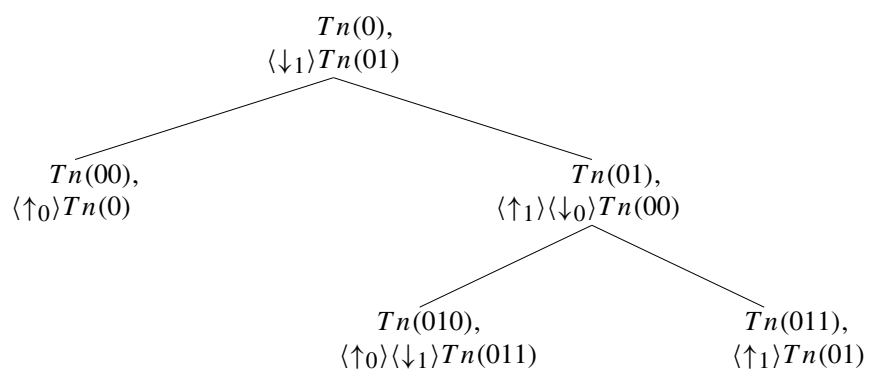

In the above tree, all nodes have a treenode address, noted with the monadic predicate $T n$ plus a unique treenode identifier, and a further statement identifying another node in the tree. For example, the statement $\left\langle\uparrow_{0}\right\rangle\left\langle\downarrow_{1}\right\rangle \operatorname{Tn}(011)$ found in the 010 node reads as: you will find treenode 011 if you take a step across the 0 mother relation followed by a step across the 1 daughter relation. Furthermore, the two kleene operators $*$ and + are used in combination with the basic tree relations, denoting the reflexive transitive and the transitive closure of the tree relation in each case. Thus, $\left\langle\downarrow^{*}\right\rangle \operatorname{Tn}(x)$ reads as $\operatorname{Tn}(x)$ holds at the current node or at a node below the current one (of arbitrary depth), whereas $\left\langle\downarrow^{+}\right\rangle \operatorname{Tn}(x)$ reads as $\operatorname{Tn}(x)$ holds at a node below the current one.

\footnotetext{
9 Fo and Ty are monadic predicates. Fo is an one place predicate that takes a logical term, formula or metavariable as its argument, where Ty a semantic type. $F o(x), T y(e)$ found on a treenode read as: the semantic content is $x$ and its semantic type is $y$.

10 There are a number of rules as regards pointer movement. See Kempson et al. (2001) and Cann et al. (2005) for more information on this.
} 
At the heart of DS, lies a system of procedures, an action based system comprised of two main types of actions: lexical and computational. The former are language specific actions/rules, roughly the lexical entries for individual words. An example of a lexical action/rule is shown below:

\section{Lexical entry for Bill}

$$
\begin{array}{ll}
\text { IF } & ? T y(e) \\
\text { THEN } & \operatorname{put}\left(\left(T y(e), F o\left(B i l l^{\prime}\right)\right)\right. \\
\text { ELSE } & \text { abort }
\end{array}
$$

The above example reads as follows: if you are at a node that has a type $e$ requirement, then decorate this node with a type $e$ value and a formula value representing the concept Bill'. In any other case abort. In that sense, a proper noun like Bill in English will be able to be parsed as soon as a node has a requirement for a type $e$. This will allow a word like Bill to be parsed either as a subject or as an object in English. Notice that everything is defined via means of actions. In the above example, the action put() instructs the system to add whatever is contained in the scope of the action to the node under consideration (the node where the pointer currently is). To give a more elaborate example, consider the lexical entry for accusative neuter clitic to "it" in SMG, given in Chatzikyriakidis (2010a):

(29) Lexical entry for the third person accusative clitic to 'it' in SMG

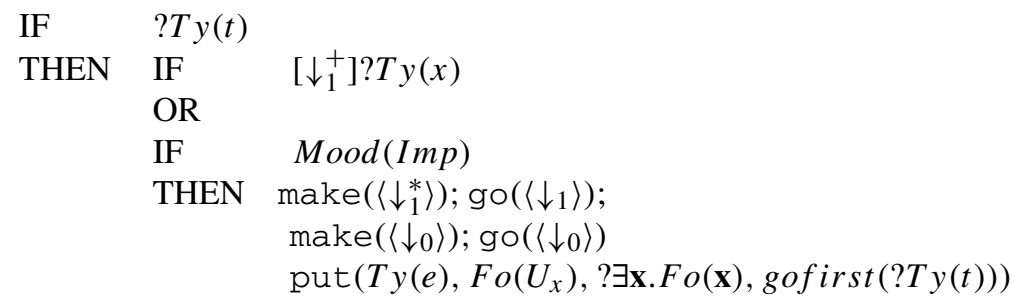

ELSE abort

As we said, in DS, syntax is seen as the growth of transparent semantic representations. According to this view, morphosyntactic phenomena are also seen in this way. There are different ways in which morphosyntax operates in DS, ranging from providing purely procedural, declarative information providing underspecified semantic representations or in some cases fully-fledged semantic representations. For example, for case marking languages, the above lexical entry given for English would involve further information besides positing a formula value and a type $e$. It will further involve a tree requirement that the node immediately dominating the current node is the predicate, it will impose in this way the requirement that the present node is the accusative node. Let us assume a language with constructive accusative. Then, the English entry would be transformed to something like the following:

Structural accusative case marked proper name

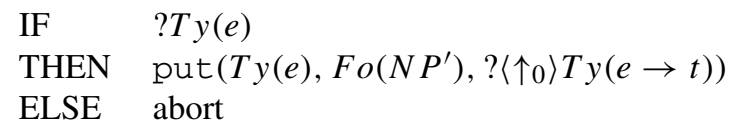


Computational rules are general computational devices behind DS and are assumed to comprise the basic tree construction mechanism. They are assumed to be a closed set of rules universally available to every language. This closed set is basically rules that help the parsing process unfold. These involve pointer movement rules, rules that perform functional application and modus ponens (for formulas and types respectively) or rules that get rid of requirements as soon as these are satisfied. A characteristic case of a computational rule is the rule of ELIMINATION. This rule performs functional application on formulas and modus ponens on types, in case both the argument and the function nodes bear complete formula and type values. So, in the example below, the bottom nodes are combined by functional application and modus ponens in order to produce the result at the node above in the second tree (the node where the pointer, $\diamond$, is at): ${ }^{11}$

\section{ELIMINATION}

Before ELIMINATION

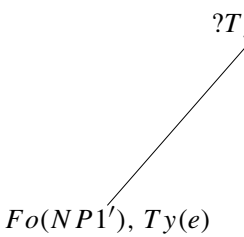

$? T y(t)$

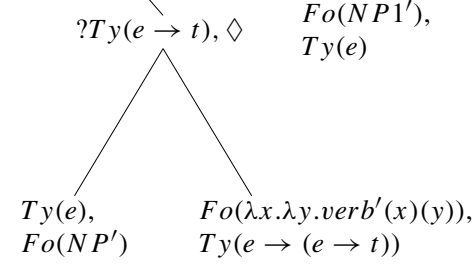

After ELIMINATION

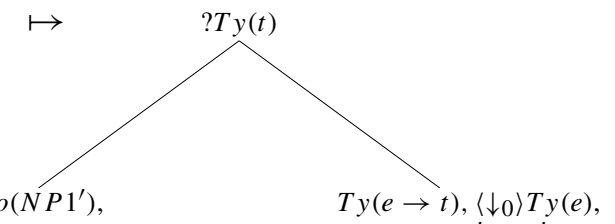

Fo $\left(\lambda y \cdot \operatorname{verb}^{\prime}\left(N P^{\prime}\right)(y)\right), \diamond$

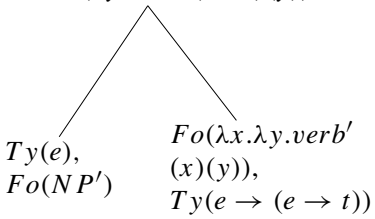

\subsection{Structural Underspecification: Unfixed Nodes}

Content as well as unfolding tree structure is allowed to be underspecified in DS. While content underspecification has been largely employed within the formal semantics literature of the past 30 years, no attempts to move underspecification into the area of syntax have been made. Structural underspecification in DS manages to deal with a range of phenomena, i.e. scrambling, clitic doubling and person restrictions to name a few (see Kempson and Kiaer 2010; Chatzikyriakidis 2010a; Chatzikyriakidis and Kempson 2011 respectively). The basic mechanism used in order to express structural underspecification is unfixed nodes. Unfixed nodes are nodes that have not yet found their position in the tree structure. As such, they are structurally underspecified at the

\footnotetext{
11 We show the effect of these rules in tree notation. See Kempson et al. (2001) and Cann et al. (2005) for the actual rules.
} 
time they are introduced. However, they need to be updated later on in order for the parse to be successful; otherwise, outstanding requirements remain, i.e. a requirement for a proper treenode address to be found $(? \exists \mathbf{x} \cdot \operatorname{Tn}(\mathbf{x}))$ and the tree update fails. The rule of $*$ ADJUNCTION introduces an unfixed node:

*ADJUNCTION: Introducing an unfixed node

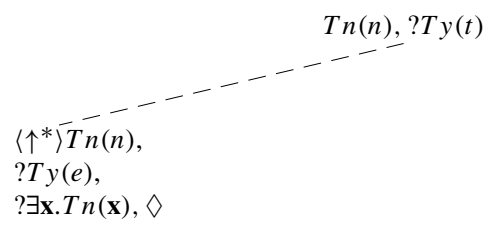

The node is structurally underspecified since it does not carry a fixed treenode address. The only thing the node "knows" as regards its treenode position is that somewhere up above or at the current node, $\operatorname{Tn}(n)$ must be found. ${ }^{12}$ The *ADJUNCTION rule works neatly for OV focus cases in Greek. In such structures, the preposed object is parsed on an unfixed node. Then, the verb is parsed, projecting the rest of the propositional structure, a type $e$ and a formula metavariable at the subject node (for the subject drop properties) and leaving a requirement for a type value in the object node: ${ }^{13}$

After parsing the verb in ton Giani xtipise, 's/he hit John'

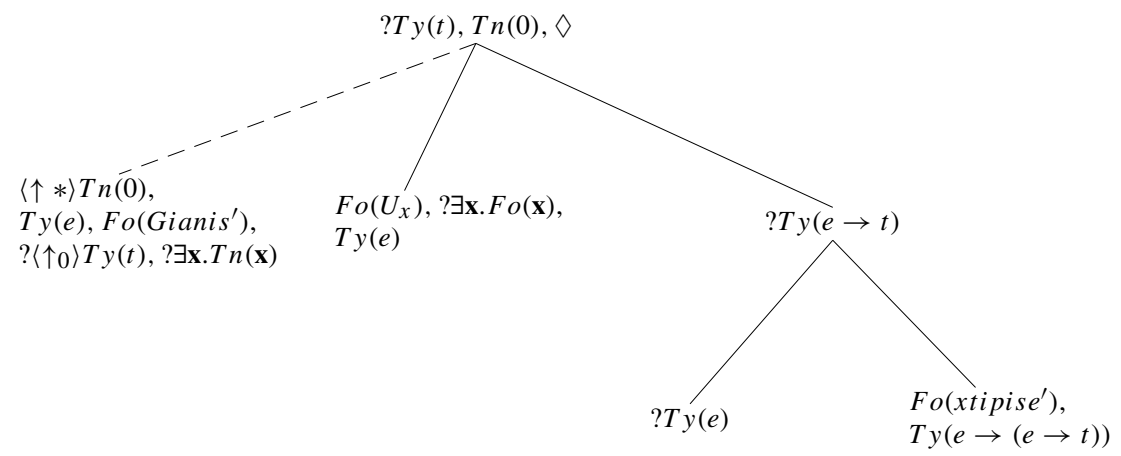

In the above structure there is an unfixed node with a type and a formula value and an open slot decorated with a type $e$ requirement (the 010 node). It is at that point that a process of unification between the unfixed node and the fixed object node (010) can take place using MERGE. MERGE is a computational rule which unifies two nodes just in case one of the two updates the treenode address of the other. The notion of update is defined by treenode address entailment. If a treenode address entails another treenode

\footnotetext{
12 Notice that the reflexive satisfaction of the * in which the node unifies with its host trivially is not possible. $\operatorname{Tn}(n)$ is the treenode address of the type $t$ requiring node. In that sense, the only way such a reflexive satisfaction will hold is in case the unfixed node unifies with the type $t$ requiring node. However, such unification is impossible, given the incompatible specifications of the respective type requirements $(? T y(e)$ and ?Ty $(t))$.

13 The lambdas are going to be omitted from this point on for ease of exposition.
} 
address, then the former can be seen as an update of the latter. ${ }^{14}$ The treenode address of the direct object node (010) can be a proper update of the underspecified address the unfixed node carries. Furthermore, the fact that the 010 node has a proper treenode address will eliminate the requirement of the unfixed node that a fixed treenode address should be found $(? \exists \mathbf{x} \operatorname{Tn}(\mathbf{x}))$. The trees below display the tree structure before and after MERGE has applied:

\section{Before MERGE}

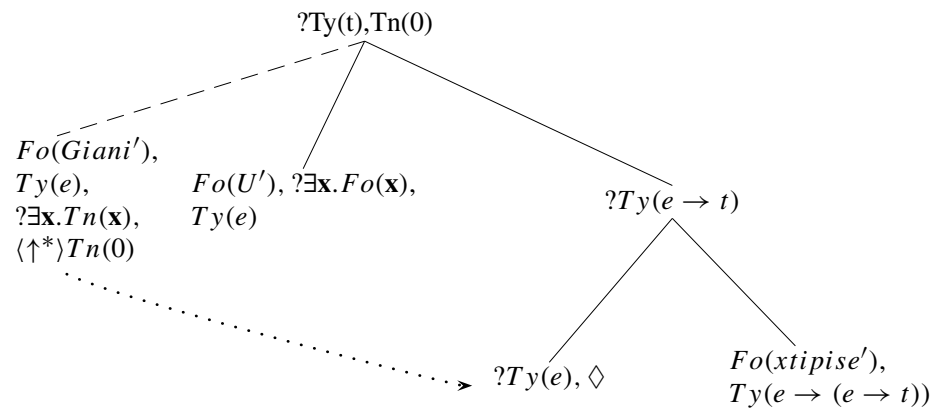

(35)

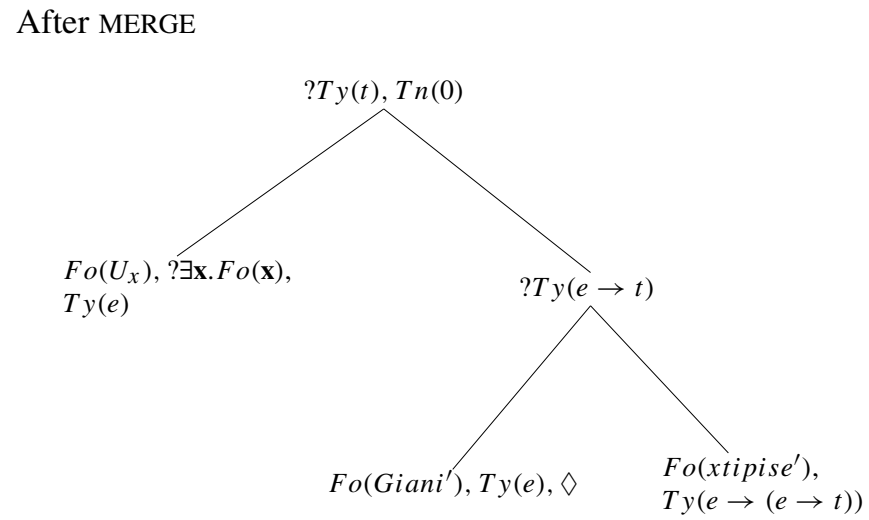

\subsection{Parsing in Context: LINK Structures}

Besides the tree structures in which each sentence involves a single tree (regardless of tree embedding), DS also makes use of pairs of trees which are linked to each other via a relation called LINK. LINK structures involve two separate tree structures. The node from which the LINK starts can be seen as setting the context in which the LINKed tree is going to be parsed. Examples of LINK relations include relative clauses, in which case the relative clause is parsed within the context of the head noun, or Hanging Topic Left Dislocation (HTLD) constructions in which case the HTLD sentence is parsed within the context of having parsed the left-dislocated element first. LINK structures have a variety of uses in DS. Let us illustrate LINK structures in more detail by looking

\footnotetext{
14 See Kempson et al. (2001) for the formal details of the rule.
} 
at an HTLD example. In order to analyse HTLD constructions, Cann et al. (2005) define two rules which link a type $e$ node where the dislocated element is parsed to a type $t$ requiring node, where the rest of the HTLD structure is parsed. The first rule introduces a LINK transition from a type $e$ requiring node to a type $t$ requiring node, while leaving the pointer in the first of the two. The second rule introduces a requirement for a shared term as soon as the dislocated element is parsed. In parsing an HTLD sentence like the one shown in (36), we apply the first rule (TOPIC STRUCTURE INTRODUCTION) that introduces the type $e$ requiring node. The NP is parsed on that node and then the second rule takes effect moving the pointer to the type $t$ requiring node and positing (on the same node) a requirement that a copy of the formula found in the node where the LINK begins must be found somewhere in the LINKed tree or to a tree LINKed to the LINKed tree $\left(?\langle D\rangle\right.$ Fo $\left(\right.$ Giorgos $\left.\left.^{\prime}\right)\right)$. In order to be able to talk about LINK relations in our tree language, we introduce the $\langle L\rangle$ relation and its inverse $\left\langle L^{-1}\right\rangle$, which are used to refer to LINK relations ( $L$ referring to a LINKed node and $\left\langle L^{-1}\right\rangle$ for a node that a LINK starts). $D$ is a generalisation of the unfixed node modality $\left\langle\downarrow^{*}\right\rangle$ that further includes the LINK relation: ${ }^{15}$

O Giorgos, ton gnorizo.

the.NOM George.NOM know.1SG him.CL- ACC

'I know George'

$\langle L\rangle \operatorname{Tn}(0), \operatorname{Tn}(n), \quad\left\langle L^{-1}\right\rangle \operatorname{Tn}(n), ? T y(t), ?\langle D\rangle$ Fo $_{\left(\text {Giorgos }^{\prime}\right)}$
Fo $\left(\operatorname{Giorgos}^{\prime}\right),[\downarrow] \top$,
$\operatorname{Ty}(e)$

In simple terms, the result of the two rules is to project a LINK relation from the HTLDed topic $o$ Giorgos. Then, in this new tree, the rest of the sentence is going to be parsed. The requirement that a copy of the HTLDed NP must be found in the LINKed tree will be satisfied as soon as the object clitic is parsed.

\section{The Koine Greek clitic System: A Case of a Pragmatically-Governed System}

An alternative way of looking at the KG data is to assume that the various syntactic constraints proposed in order to capture clitic positioning in KG or the different competing grammar subsystems exhibiting different syntactic constraints (as in Pappas (2004b)) are actually not there. Following Bouzouita (2008) building on Pickering and Garrod (2004), I argue that the clitic positioning system of KG is not governed by syntactic constraints but rather by underlying pragmatic preferences. Within this line of reasoning, I argue that the complicated picture arising from the $\mathrm{KG}$ data is the result of a number of positioning tendencies depending on a pragmatically governed clitic positioning system. But, what does it mean to have a pragmatically governed clitic system? I take this to mean that you have a system where the syntactic apparatus

\footnotetext{
15 The interested reader is directed to Cann et al. (2005) and Chatzikyriakidis (2010a) for the formal details of the LINK rules.
} 
allows both proclisis and enclisis in all cases, and the actual choice of proclisis or enclisis is done based on factors which are pragmatic and not syntactic in nature.

The system can develop positioning tendencies, but these remain tendencies and cannot be explained by assuming that these are, in fact, the product of syntactic rules. Assuming fixed syntactic rules will not be able to predict the desired variation attested. One way to explain the proclitic instances is to assume a general tendency for anaphoric elements to appear as early in the clause as possible, to allow for anaphoric construal as early as possible. This is something that has already been noted in the literature for Latin by Kempson and Cann (2008), and the data from KG seem to suggest the same tendencies are at play for KG. Proclisis with Wh-elements, complementisers and negation (among others) can be explained assuming that clitics tend to appear as early as possible once identification of an emergent propositional domain is possible. All these elements make this identification possible, so proclisis emerges. It is this tendency that gets routinised and turned into a syntactic constraint in the medieval varieties.

Let us assume that such a pragmatically-governed system is what is at play in KG. By doing so, a surprisingly neat and economical account of the KG clitic facts can be achieved, by making the, at first sight, extravagant assumption that no restrictions exist in the entry for KG clitics at all. This may seem to be an extreme position but by taking a closer look, one will realize that such an assumption is not that extravagant in the end. In fact within the DS system this can be handled in a straightforward manner. Before the consequences of such a a proposal are discussed, let us first see how the lexical entry for $\mathrm{KG}$ clitics is to be formulated. Encoding no restrictions in the entry means that the only thing we need is an initial trigger. This trigger would be assumed to be a type $t$ requiring node. Given that this trigger is satisfied, parsing of the clitic can proceed. A sample lexical entry where all formal detail is omitted except this initial parsing trigger is shown below:

Sample lexical entry

IF $\quad ? T y(t)$ [Triggering point]

THEN ACTIONS

ELSE abort

The only restriction encoded in the entry is that the pointer, i.e. the mechanism which tracks the node in which the parsing process is at a given stage, is at a type $t$ requiring node. The type $t$ requiring node is the node where the parsing process begins, as well as the node where the pointer is when any of the elements that trigger proclisis in KG (negation markers, subordinating conjunctions, Wh-elements, fronted elements) or after a verb has been parsed, under standard DS assumptions (see Chatzikyriakidis (2010a) for the formal details). ${ }^{16}$ With this entry, the robust variation found in $\mathrm{KG}$ can

\footnotetext{
16 Note that the entry as it is will also predict sentence initial clitics to be possible according to the data in the Oxyrynchus Papyri. However, given that no sentence initial clitics are found in the other KG texts such as the New Testament or The Shepherd of Hermas, someone might argue that indeed a restriction on sentence initial clitics exists. In case this is true, a slight modification in the entry will ban first position clitics. This modification involves a further condition which will state that something must hold below the type $t$ requiring node in order for the clitic to get parsed. See Chatzikyriakidis (2010a) for the exact formal details of this modification.
} 
be easily explained, given that both options (preverbal and postverbal) ${ }^{17}$ are allowed by the parser/grammar in all cases. For example, variation with the complementiser hina as this is exemplified in (38) and (39) is explained given that both after hina and after the verb is parsed the pointer, i.e the tracking mechanism, will be at the ?Ty(t) node. Given that this node acts as the clitic's triggering point, both cases are predicted to be possible:

epimelou seautēs hina moi hugiainēs

take-care/2SG of-yourself so-that me.CL- DAT are-healthy.2G

'take care of yourself so that you will be in good health for my sake' [Oxy: 1154, apud Pappas, 2006: 323]

takhu erkhei hina idōmen se quickly come so-that see.SUBJ you.CL- ACC

'Come quickly, so that we may see you.' [Oxy: 2599, apud Pappas 2006: 323]

Under this analysis, the apparent syntactic restrictions are the result of pragmatic preferences rather than syntactic constraints. These pragmatic preferences can be relevance-driven, a claim already made by Bouzouita (2008) and Kempson and Cann (2008) for Latin weak pronouns. According to Bouzouita, an explanation for the Latin weak pronoun system can be given assuming a processing effort minimisation account in the sense of Kempson and Cann (2008). There, the authors argue that clitics being anaphoric expressions, need to be identified by a substituent in the context. It is then argued that parsers require the search space for such substituents to be as small as possible in order for cognitive effort to be minimised under general relevance theoretic considerations (Sperber and Wilson 1995). If this is correct, then anaphoric expressions should appear as early in the clause as possible as a strategy aiming to minimise search space. In the case of Latin, weak pronouns indeed tend to appear immediately after an emergent propositional domain has been established. Such an emergent propositional domain is signalled by all the elements triggering proclisis in Latin, for example negation markers, subordinating conjunctions and Wh-elements. The situation in KG seems to exhibit similar patterns, with clitics also tending to appear after a propositional domain has been established. However, unlike Latin, in which no sentence initial clitics were possible, $\mathrm{KG}$ as we have already said seems to allow sentence initial clitics, although extremely rare. In that sense no Tobler-Mussafia like restriction (first position restriction) needs to be encoded in the entry for KG clitics. Abstracting away from the specifics of each language, both Latin and KG present a remarkably similar picture in terms of positioning, making a common explanation plausible for both.

\footnotetext{
17 With the exception of infinitives. Note that we have not encoded this stricter position with infinitives in the entry. This is because we believe that this positioning should be captured via the entry for infinitives, which would not allow parsing of an infinitive in the presence of a clitic pronoun. We leave the details of this idea as a subject for future research.
} 


\section{The Transition from Koine to Medieval Greek}

Taking a look at the Medieval Greek data, one notices a shift towards the categorical association of a number of environments with proclisis. The tables below present the data of Mainland Medieval Greek (MMG) as well as the data from Medieval Cypriot and Pontic Greek (MCG and MPG):

(40) Clitic positioning in MMG, adapted from Pappas (2004b)

\begin{tabular}{|r|r|r|}
\hline Environment & Preverbal & Postverbal \\
\hline Clause initial & 59 & 719 \\
\hline Coordinating conjunction & 58 & 681 \\
\hline oti "that" & 8 & 30 \\
\hline sioti "because" & 4 & 0 \\
\hline Reduplicated object & 39 & 79 \\
\hline Wh-elements & 439 & 5 \\
\hline Negation markers & 431 & 3 \\
\hline na"to, in order to" & 1436 & 4 \\
\hline ina "to, in order to" & 24 & 0 \\
\hline particle as "let" & 65 & 1 \\
\hline an, ean "if" & 324 & 2 \\
\hline pos "that" & 3 & 9 \\
\hline Object,PP,non-temporal adverb & 898 & 90 \\
\hline Subject & 334 & 130 \\
\hline Temporal expression & 86 & 63 \\
\hline Imperatives & 25 & 305 \\
\hline
\end{tabular}

(41) Clitic positioning in the Cypriot Chronicles, adapted from Pappas (2004b)

\begin{tabular}{|r|r|r|}
\hline Environment & Preverbal & Postverbal \\
\hline Clause initial & 0 & 208 \\
\hline Reduplicated object & 0 & 15 \\
\hline Function word & 101 & 3 \\
\hline Fronted constituent & 1 & 14 \\
\hline Subject & 0 & 29 \\
\hline Gerund & 0 & 19 \\
\hline Imperative & 0 & 4 \\
\hline
\end{tabular}

(42) Clitic placement in MPG, adapted from Pappas (2004b) 


\begin{tabular}{|r|r|r|r|}
\hline Environment & Preverbal & Postverbal & Date \\
\hline Clause initial & 0 & 19 & 13th, 14th, 15th \\
\hline Fronted constituent & 0 & 10 & 13 th \\
\hline Temporal expression & 0 & 3 & 13th, 14th, 15th \\
\hline negative marker ouk & 0 & 1 & 13 th \\
\hline kathōs "while, since" & 0 & 2 & 13 th \\
\hline complementiser epei "when" & 0 & 1 & 13 th \\
\hline complementiser hina "to, in order to" & 14 & 0 & 13 th \\
\hline particle as "let" & 1 & 0 & 13 th \\
\hline negation marker mē & 1 & 0 & 13 th \\
\hline complementiser ōs (causal/temporal) & 1 & 0 & 13 th \\
\hline Subject & 1 & 1 & 13 th \\
\hline Wh-expression & 7 & 19 & 13th, 14th, 15th \\
\hline
\end{tabular}

The first thing one notes when comparing the medieval varieties to $\mathrm{KG}$ is that the environments that are unstable in the KG system, in the sense that they exhibit variation, tend to become fixed in the medieval varieties by choosing one of the two possibilities, enclisis or proclisis. This is for example the case for Wh-elements, the negation marker $m \bar{e}$ and subordinate conjunctions in MMG and MCG (note that in the MCG table all these elements are grouped as a common category, i.e. function word). MPG on the other hand, does not follow MMG and MCG and presents a more conservative picture with proclisis being categorical only with the complementiser hina 'in order to'. There are instances of categorical preverbal placement with some complementisers and categorical enclitic placement with others but the number of tokens is too small to be conclusive (e.g. complementiser $\bar{o} s$ associated with enclisis has only one token). Sentence initial clitics are not found in MCG and MPG but are found in MMG.

In what follows, I will argue, in line with Bouzouita (2008), that the transition from $\mathrm{KG}$ to the medieval varieties can be summarized as follows: the pragmatic reasoning governing the $\mathrm{KG}$ clitic system was progressively lost and gave rise to stricter positioning systems where pragmatic preferences were lexically encoded as syntactic restrictions. This whole process of syntactic constraints substituting pragmatic preferences can be explained as a routinisation process in the sense of Pickering and Garrod (2004). Routinisation is in itself a very common concept in the psycholinguistic literature (Garrod and Pickering 2004; Pickering and Garrod 2004; Ruh et al. 2005) and can be seen as a process establishing a number of routines that reduce cognitive load, in effect parsing shortcuts. According to Pickering and Garrod (2005), a routine is "an expression that is "fixed" to a relatively great extent". Routinisation is something like long-term alignment. Short-term alignment can occur between dialogue participants within the time span of only a few sentences. Alignment can range from low-level lex- 
ical alignment to pure syntactic alignment (Garrod and Doherty 1994; Branigan et al. 2005). ${ }^{18}$ Once these alignment patterns get repeated, they are stored in the memory as routines. This long-term alignment is what we call routinisation. ${ }^{19}$ Bouzouita (2008) using this concept of routinisation, argues that syntactic change is in fact driven by routinisation. ${ }^{20}$ In our case, the repetition of a number of clitic positioning patterns that had an underlying pragmatic basis, got routinised and became a kind of a processing shortcut. Once this had happened, the pragmatic basis was lost and subsequently replaced by the encoding of these routinisations as syntactic constraints inside the lexicon.

In terms of syntactic encoding within the DS framework, what we get is the emergence of additional requirements in the triggering point of the clitic's entry. These additional restrictions arise as generalised parsing strategies, in the sense that a specific parsing strategy used for parsing a number of elements can end up being a parsing trigger. For example, we can categorize the proclitic triggers in MMG in two different categories depending on the strategy used in each case. Fronted elements and Wh-elements in DS are assumed to be parsed on an unfixed node, a structurally underspecified treenode in which no information about its syntactic position is yet known:

\section{The rule of $*$ ADJUNCTION}

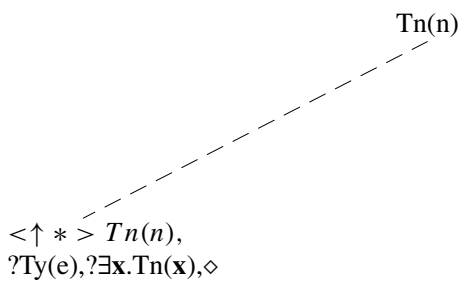

Tense/aspect and negation markers, as well as subordinating conjunctions, are assumed to project a requirement for an event node. This event node is the locus where all aspect/tense properties are encoded (?T $y\left(e_{s}\right)$, see Chatzikyriakidis (2010b) and Cann (2010) for more details). The transition to MMG involves the emergence of these two parsing strategies as triggers for parsing the clitic. These two strategies along with an additional trigger capturing enclitic positioning comprise the entry for MMG:

\footnotetext{
18 However, pure syntactic alignment in the course of short dialogues has been disputed by work from Healey et al. (2014), where the claim there is that people actually syntactically diverge in the course of adjacent turns.

19 A similar scenario is presented in Pappas (2004b).

${ }^{20}$ As Bouzouita aptly notes the concept of routinisation has intriguing similarities with a number of other terms (automatisation, syntactisation) proposed in the historical linguistics literature. See Bouzouita (2008) for discussion and references.
} 
The entry for MMG

$\begin{array}{llll}\text { IF } & & ? T y(t) & \\ \text { THEN } & \text { IF } & \langle\downarrow *\rangle \exists x . T n(x) \mid & \text { [Unfixed node trigger] } \\ & & \langle\downarrow 0\rangle ? T y\left(e_{s}\right) \| & \text { [Situation argument trigger] } \\ & & \left\langle\downarrow{ }_{1}^{+}\right\rangle T(x) & \text { [Enclitic trigger] } \\ & \text { THEN } & \text { ACTIONS } & \\ & \text { ELSE } & \text { abort } & \end{array}$

ELSE abort

Where $\mid=$ OR (inclusive disjunction) and $\|=$ XOR (exclusive disjunction)

Looking at MCG, we see that proclisis has been generalised in fewer environments compared to MMG. Specifically, MCG has not yet generalised fronted constituents as proclitic triggers. Thus, the basic difference between MMG and MCG is that in MCG, fronted elements do not trigger proclisis. In this respect, we can assume that the unfixed node trigger is not yet generalised but applies to Wh-elements only. As such, the entry for MCG will be the same as the one for MMG except that the unfixed node trigger will be specified to apply to Wh-elements only:

Lexical entry for Medieval Cypriot

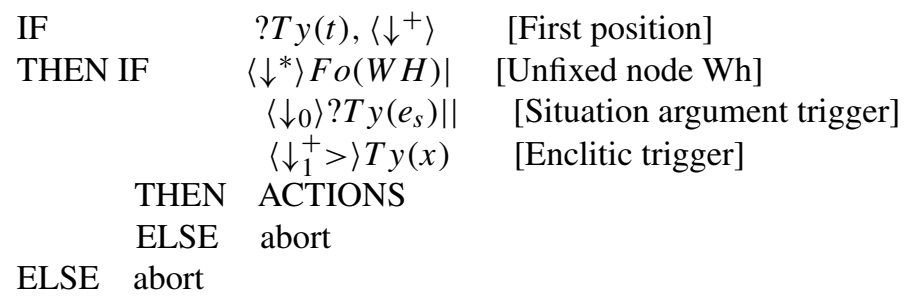

Lastly, MPG is the most conservative of the three varieties in the sense that spread of proclisis is strikingly more limited than in both MMG and MCG. The only environment that is categorically related to proclisis is complementiser hina, "in order to". There are other instances of categoricality, e.g. enclisis with temporal and dubitative conjunctions epei and mēpōs respectively, but the number of tokens is too small to derive a safe conclusion. Our account will have to rely on the data available, even though these, as said, cannot be decisive with respect to a number of environments. The situation as presented by the data can be described framework-independently as a situation where fronting does not play a role in clitic positioning, ${ }^{21}$ and proclisis is not generalised as regards subordinating conjunctions and Wh-elements. From a DS perspective, MPG presents a system where a highly disjunctive entry has to be encoded in order to deal with the data, since no generalised strategy as in the case of the other two varieties can be used. We will see that this highly disjunctive entry can be claimed to be the reason for the strictly enclitic system we find in modern day Pontic Greek. The lexical entry for MPG is shown below:

\footnotetext{
21 10/10 cases where a fronted constituent is present are associated with enclisis, 11/12 if we assume that we are dealing with fronted subjects in the two cases at hand.
} 
(46) The entry for MPG

$\begin{array}{lll}\text { IF } & ? T y(t) & \\ \text { THEN IF } & +h i n a \mid & {[\mathrm{CONJ}]} \\ & +\mid \overline{\mathrm{o}} s & {[\mathrm{CONJ}]} \\ & +a s \mid & {[\mathrm{CONJ}]} \\ & \left\langle\downarrow^{*}\right\rangle F o(\neg \lambda P(\epsilon, P)) \mid[\mathrm{NEG}] \\ & \left\langle\downarrow^{*}\right\rangle ?\langle\uparrow 0\rangle T y(t) \| & {[\mathrm{FR} . \text { SUBJECT] }} \\ & \left\langle\downarrow_{1}^{+}\right\rangle T y(x) \mid & \text { [ENCLITIC TRIGGER] } \\ & \left\langle\downarrow^{*}\right\rangle F o(W H) & \text { [WH] } \\ & & \\ & \text { ACTIONS } & \\ \text { THEN } & \text { abort } & \\ \text { ELSE } & & \end{array}$

ELSE abort

Summarizing, I argued that the transition from KG to MG involves the loss of an underlying pragmatic basis and the encoding of this underlying pragmatic basis into syntactic constraints via routinisation. The effect of this routinisation process is not the same in all varieties of MG, and as such we get different systems depending on the number of environments formerly associated with pragmatic preferences end up being encoded as syntactic constraints. We will see that this difference in the number of proclitic environments that got routinised and encoded as syntactic constraints will play a major role in the way the respective MG systems have developed.

\section{The Transition from Medieval to Modern Greek}

The next step in giving a diachronic account of clitic placement of the varieties presented is to see how the medieval ancestors of these have developed into today's systems. Starting with SMG we notice that its clitic system is exclusively verb centred, with proclisis being generalised to all finite verbs, while enclisis being retained only for non-finite verbal forms, i.e. imperatives and gerunds. The system of MMG, on the other hand, is a system where given the absence of proclitic environments, enclisis obtains. In that sense, the form/mood of the verb does not seem to play any role in clitic positioning in MMG, or better put: in the absence of any proclitic triggers, all forms/moods of the verb give rise to enclisis.

The question that arises is how such a non-verb centered system like the one exhibited by MMG gave rise to the respective SMG system. ${ }^{22}$ In our discussion regarding the clitic systems of the medieval varieties of Greek, we have seen that MMG exhibited the biggest number of proclitic environments when compared with MCG and MPG. Thus, proclisis is more generalised in MMG than in MCG or MPG. This informal observation might be the key in explaining the transition from one system to the other. Note that in the case of MMG, a number of sentence initial clitics can be also found.

\footnotetext{
22 What is meant with the term "verb-centered" here is not whether the clitic always cliticises to the verb or not, but rather whether the form of the verb plays a role in clitic positioning or not, regardless of the element that the clitic attaches to. For the first issue see the Condoravdi \& Kiparsky-Pappas debate (Condoravdi and Kiparsky 2002; Pappas 2004a).
} 
The number of tokens is not negligible and indeed might point out that a process towards a verb centered system is already taking place in MMG (59/778).

Further evidence might come from the number of proclitic tokens in environments involving coordinating conjunctions (58/739). The question arising is the following: what is the trigger and nature of this process? Bouzouita (2008) in discussing the transition from Medieval Spanish (MedSp) to Renaissance Spanish (ReSp) and from Resp to Modern Spanish (ModSp), argues that both routinisation and re-analysis are at play. The argument is that once the pragmatic basis of the Latin system got lost, pragmatic preferences were encoded in the lexicon of MedSp. The loss of the pragmatic basis, led to a speaker/hearer mismatch, since the existence of alternative parsing strategies for parsing one and the same lexical element could easily lead to a situation where the parsing strategy used by the speaker and the one parsed by the hearer do not match (e.g. an unfixed node used by the speaker is analysed as a LINK from the hearer). However, unlike SMG that exhibits a similar development to the ModSp clitic system, the systems of CG and PG are completely different and, as such, can be used as a further testing ground for the "routinisation driving syntactic chang" hypothesis.

In the case of the transition from MMG to SMG, I am going to argue that the high number of proclitic environments ${ }^{23}$ in $\mathrm{MMG}$ is the actual cause of proclisis generalisation in SMG. ${ }^{24}$ The shift towards a generalised proclitic system seems to be already at play in MMG since a number of cases of sentence initial clitics are found, as the data from MMG in (40) seem to suggest. Besides these cases of sentence initial clitics, a number of elements triggering proclisis, namely fronted constituents are assumed in DS to be able to get parsed using different strategies, i.e. they can be parsed either on an unfixed node or on a separate tree structure that is linked to the main one via a relation called LINK. The node from which the node begins can be seen as setting the context in which the LINKed tree gets parsed. This is what arguably happens in relative clauses or in Hanging Topic Left Dislocation structures (HTLD). In the first case, the NP modified by the relative clause provides the context in which the relative clause is parsed, while in the second case the topic itself acts as the context in which the rest of the sentence is going to be parsed (see Cann et al. (2005), Gregoromichelaki (2006) and Chatzikyriakidis (2010a) for more information on the use of LINK structures to model different syntactic phenomena). Assuming this availability of different parsing strategies, I argue, following Bouzouita (2008), that, given such a situation, parsing/hearer mismatches are likely to occur. An example of such a situation where the speaker's unfixed node structure is re-analysed as a LINK by the hearer is shown below:

\footnotetext{
23 The view advocated here is that about the high numbers of proclitic environments, not number of proclitic cases, even though the count of proclitic cases is higher than enclitic ones in MMG.

24 It is worth noting that proclisis generalisation is already present in early modern Greek texts like e.g. the Chronicle of the Turkish Sultans. For more details see Vejleskov (2005).
} 
Speaker's structure

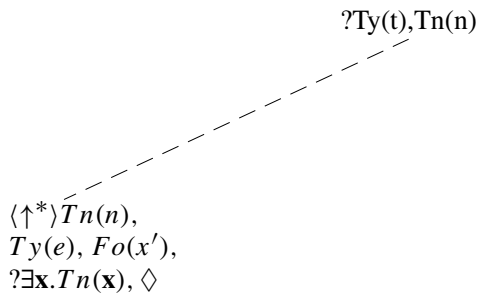

(48)

Hearer's reanalysis

$\langle L\rangle \operatorname{Tn}(0), \operatorname{Tn}(n)$

$\left\langle L^{-1}\right\rangle \operatorname{Tn}(n), ? T y(t), ?\left\langle\downarrow_{*}\right\rangle, F o\left(x^{\prime}\right), \operatorname{Tn}(0), \diamond$

Fo $\left(x^{\prime}\right)$,

$T y(e)$

Given a generalisation of the LINK strategy, the number of elements causing proclisis is now vast, since all preverbal arguments, all conjunctions and all modality/tense markers are now associated with proclisis. With this spread of proclisis the result was that the proclitic triggers were not discernible anymore. Within this context, the next step involves generalisation of the initial ?Ty $(t)$ trigger by collapsing all the embedded proclitic triggers and developing a general proclitic trigger which ensures that no verb has been parsed. Given that almost all elements appearing before the verb could cause proclisis due to parser/hearer mismatches, the development of a general trigger ensuring that no verb has been parsed, as well as the collapse of all proclitic triggers in favour of this more general proclitic trigger are not implausible. However, generalisation of proclisis, with the exception of focussed constituents, involved only finite forms and as such the ability of non-finite contexts ${ }^{25}$ to retain enclitic dominance was due to the fact that most of the elements triggering proclisis were incompatible with non-finite forms (Wh-elements, complementisers, subordinating conjunctions, modal and tense particles are impossible in non-finite environments). Consequently, the enclitic trigger, even though retained, was modified to apply only for non-finite elements (imperatives and gerunds in SMG). Thus, the entry arising was one where a general proclitic and an enclitic trigger applying only to imperatives and gerunds arose:

The transition from MMG to SMG

\footnotetext{
25 The term non-finite is used in a pre-theoretical sense here. As such, it does not bear any of the usual assumptions that the term usually carries, e.g. the assumption that imperatives have no tense. For the case at hand, I will non-finite refers to imperatives and gerunds.
} 


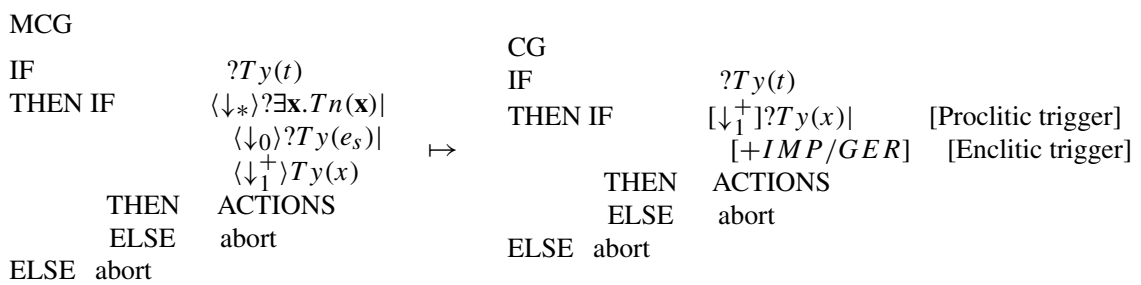

In the case of $\mathrm{CG}$, what we see is the transition between two systems which from a first look seem almost the same, since both are in general enclitic except when a number of proclisis inducing elements appear in the left periphery. However, taking a closer look at the two stages of CG, one notices that, descriptively, the transition between the two stages involves the emergence of more proclisis-inducing environments. ${ }^{26}$ Specifically, in MCG fronted constituents are not associated with proclisis, while in CG the situation is different with these elements functioning as proclisisinducing triggers. Thus, the transition from MCG to CG involves the emergence of a number of new proclitic environments: fronted objects/subjects, fronted adverbs, fronted PPs/temporal expressions. Abstracting away from the number of these environments, we can assume that the new proclitic environment is actually one, i.e. a fronted element at the left periphery. One of the strategies associated with fronted elements in DS, is the use of unfixed nodes, i.e. the projection of nodes that have not yet been identified structurally in the tree structure. Now, the question is how this rise in proclitic environments took place. In MCG, we had to use the unfixed node strategy as specifically applying to Wh-elements only in order to capture MCG clitic positioning. Then, the transition to CG will involve the transition from a general trigger as applied to a specific environment to this general trigger as applied to all environments it can be used. In other words, we have the transition from a case specific to a case neutral trigger. In case of actual encoding, we have the drop of the restriction $F o(W H)$ and, thus, the simplification of the entry, that now covers more syntactic environments. Note that this change is in line with the findings in Bouzouita (2008) in the transition from Medieval to Renaisance. There, as well, a restriction got lost, causing the generalisation of proclisis. The transition is shown below: ${ }^{27}$

\footnotetext{
26 Pappas (2008) mentions that even though the number of proclitic environments are indeed more in CG, he also mentions that a number of enclitic environments also arise in CG. Thus, he argues that the claim that there is a tendency towards proclitic positioning is not well-founded. However, this is not entirely true, since the enclitic inducing environments that Pappas refers to are those involving the complex negation/subordination particles with $t z e$ as the second element of the complex. These elements were not present in MCG and thus we do not know what their behaviour would be. However, attributing enclisis in these cases to the presence of $t z e$, no additional enclitic envrironments need to be assumed given that $t z e$ and in general coordinating conjunctions are associated with enclisis in both MCG and CG. In this respect, the claim that there is a tendency towards proclitic positioning does not seem to be contradicted by Pappas' claim.

27 For more details as regards the DS analysis of CG see Chatzikyriakidis (2012).
} 
(50) The transition from MCG to $\mathrm{CG}$

\begin{tabular}{|c|c|}
\hline MCG & \\
\hline IF & $? T y(t)$ \\
\hline THEN IF & $\begin{array}{l}\left\langle\downarrow_{*}\right\rangle ? \exists \mathbf{x} \cdot \operatorname{Tn}(\mathbf{x}) \wedge F o(W H) \mid \\
\left\langle\downarrow_{0}\right\rangle ? T y\left(e_{s}\right) \mid \\
\left\langle\downarrow_{1}^{+}\right\rangle \operatorname{Ty}(x)\end{array}$ \\
\hline $\begin{array}{ll} & \text { THEN } \\
\text { ELSE } & \end{array}$ & $\begin{array}{l}\text { ACTIONS } \\
\text { abort }\end{array}$ \\
\hline
\end{tabular}

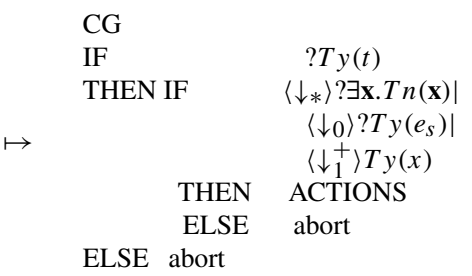

The last transition we need to look at is the transition from MPG to PG. Remember that MPG has the fewest proclitic environments compared to the other two medieval systems. However, this fact did not lead to a simpler lexical entry but to a considerably more complex one. ${ }^{28}$ This paradox is easily explained given that no generalisation across linguistic elements can be found in MPG. For example, some subordinating conjunctions are associated with proclisis, while others with enclisis or variant positioning. The effect of this situation is the emergence of a lexical entry that has to separately list all the proclitic environments, given that no proclitic generalisations can be made. Thus, even though the proclitic environments are fewer in MPG, the proclitic triggers are more than the ones found in MMG and MCG, since every element inducing proclisis is listed separately (see (46)).The lexical entry is extremely complex and shows in a very transparent way that it is extremely difficult to find generalisations within such a system, a fact already noted by Pappas (2004a). The only generalised trigger is the trigger ensuring enclisis $\left(\left\langle\downarrow_{1}^{+}\right\rangle T y(x)\right)$. Given this, and also the fact that the proclitic environments were considerably fewer than those found in the other two medieval varieties, I will argue that the reason for the transition towards a strict enclitic system in PG is totally dependent on these two previous facts. Spread of proclisis, which was the result of the generalisation of a number of parsing strategies that were used as proclitic triggers in MMG and MCG (e.g. a generalised unfixed or type $e_{s}$ node proclitic trigger as in the case of MMG), was not possible in MPG. This, in combination with the complexity of the lexical entry shown for MPG and the fact that the enclitic trigger is the only generalised trigger (spanning across all verbal types), gives us a straightforward explanation of why the PG clitic system turned out to be strictly enclitic. Since proclisis failed to be generalised or even get spread across linguistic categories or parsing strategies, and given the complexity of the entry presented above, PG clitics followed the opposite route and generalised the most general trigger of the entry, i.e. the enclitic trigger. In that sense, the transition from MPG to PG involves the drop of all proclitic triggers. The transition between the two stages is shown below:

\footnotetext{
28 Of course, we have far fewer data from MPG, so the assessment of the situation is less reliable.
} 
(51)

The Transition from MPG to PG

MPG

IF

THEN IF

THEN

ELSE

ELSE abort

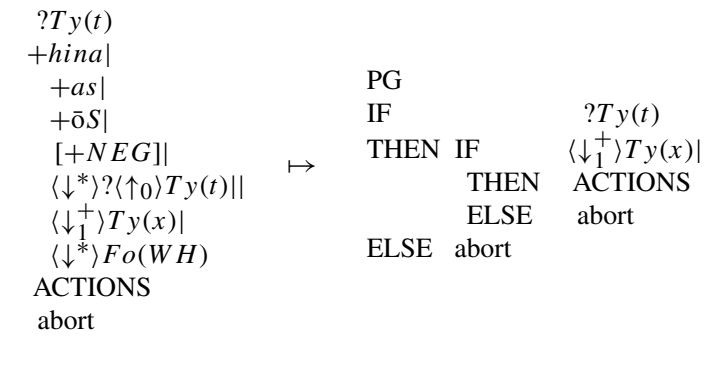

\section{Remarks on Routinisation, Processing/Parsing Mismatches and Syntactic Change}

Clitic positioning in this paper was explained to a large extent using the concept of syntactic routinisation, in effect the calcification of a number of strategies that were part of an earlier pragmatic rather than syntactic system. The interesting fact as regards the varieties discussed here, is the diverse outcomes given a common input system. Specifically, it is quite intriguing to see that all the range of clitic positioning possibilities exemplified by Standard Modern, Cypriot and Pontic Greek arose out of a single system, that of KG. Of course, the intermediate stages are also quite different in each case (the Medieval varieties), but the fact remains fascinating in any case.

A question that naturally arises is what do we learn from the fact that all these three different possibilities might arise. The first thing one can say is rather tautological and obvious: given the proposal, we take all individual developments to be reasonable outcomes of a parent system like KG. The fact that no strictly enclitic system arose in Romance can be attributed to the subsequent development of Medieval Romance and not Latin itself. Given what we have said here, an enclitic system might well have arisen from Latin. The fact that this never happened, at least to our knowledge, is something that is outside the scope of this work. Also, the fact that a number of positioning systems might arise from a system similar to KG does not mean that systems based on pragmatic considerations are not in general biased towards one pattern or the other (e.g. towards enclisis or proclisis). In the case of $\mathrm{KG}$, it is true that system seems biased towards generalising proclisis, but there is nothing in this realization that guarantees that such a proclitic system will actually arise. There is indeed more fertile ground, but what the account offers is an explanation, and not a prediction. Or better put, the account does not claim to be making any strong predictions. In cases of systems like KG and Latin, the bias indeed seems to be towards proclisis, which is indeed what we find for the vast majority of the systems that developed out of these systems (the PG clitic system stands as a notable exception). It is this proclitic bias of a system underlied by pragmatic considerations, as well as parser/hearer processing mismatches, that acted as fertile ground for routinisation to take place in the transition from KG to SMG and $\mathrm{CG}$, storing these positioning preferences as fixed lexical macros. 
Routinisation, or in general the idea that pragmatic or other kind of biases can be end up being lexical macros and eventually be hard-coded in the lexicon, and, furthermore, the idea that parsing/processing mismatches can happen in real time interaction when more than one structural route is possible to parse a number of constructions, is a promising way to look at the diachronic development of clitic positioning systems. However, it has to be taken into consideration that this account alone cannot be the whole story of syntactic change for clitic systems or syntactic change more generally, given that a number of other latent or confounding factors for syntactic change might be at play. For example, the form of $\mathrm{KG}$ that gave rise to the individual systems is taken to be the same for all three varieties. But, this is an oversimplification lacking data from individual regional varieties of $\mathrm{KG}$. We have allowed ourselves to make the simplifying assumption that $\mathrm{KG}$, is the linguistic ancestor of all Medieval Greek varieties, but, in real terms, this is unsustainable. Unfortunately, there is no way to check whether regional differences of KG might have something to do with the different outcomes we find in the Medieval varieties. It is thus impossible to tell whether a shared linguistic ancestor like $\mathrm{KG}$ gave rise to different Medieval varieties due to routinisation plus parsing/production mismatches alone affecting the syntax of a given system to varying degrees in each case, or whether these processes are the same in every case and what we are dealing with is not a common KG variety, but various different ones. The issue has to be further examined in any case. In particular, it would be of great interest to test this assumption against new sets of languages, in order to see whether the claim about routinisation plus parsing/production mismatches being one of the key factors behind language change can be sustained. One last thing to note is that if such an account is shown to be correct, then DS seems to be an ideal framework in general to formalize syntactic change based on the routinisation plus parsing/production pressures idea. The reason is simple: DS is a parsing oriented, dynamic framework. The parser is taken to be the grammar and vice versa. This makes possible for concepts like parser/hearer mismatches or parsing strategies to be part of the actual explanation. It is very difficult to conceive how these ideas could be implemented within a more mainstream theory of syntax, where the parser is considered to be separate from the actual grammar. Consequently, concepts like the parser/hearer mismatches used in the account presented here do not really make sense in a more traditional syntactic setting.

\section{Conclusions}

In this paper, I presented a diachronic account of the clitic systems of Standard Modern, Cypriot and Pontic Greek within the framework of Dynamic Syntax. I argued that the transition from KG to the respective medieval varieties involves a process of routinisation whereby an earlier system determined by pragmatic considerations (the KG clitic system) lost its underlying pragmatic basis and encoded pragmatic preferences as syntactic restrictions. The difference in the positioning systems of the modern forms of the varieties discussed is then explained by looking at the positioning systems of their respective medieval ancestors. SMG derived from a system which already started to generalise proclisis in medieval times. Proclisis was generalised via parsing strat- 
egy generalisation, i.e. a given parsing strategy used for parsing a number of elements ended up being a proclitic trigger. However, the fact that different parsing strategies were possible in parsing one and the same element (e.g. parsing fronted elements as unfixed nodes or LINK structures), gave rise to parsing/hearer mismatches, and had the result of further generalising proclisis to more environments. The proclitic environments ended up being so many that was hard to distinguish proclitic triggers anymore. All the proclitic triggers collapsed in favour of one general proclitic trigger. On the other hand, the fact that most of the elements triggering proclisis were impossible in non-finite contexts had the result of enclisis being retained in non-finite environments. The emerging SMG system kept the old enclitic trigger of MMG by modifying it to apply to non-finite verbal forms only. ${ }^{29}$ The situation is different in CG. CG derived from a system, i.e. MCG, in which proclitic environments are fewer than those found in the modern system or the medieval ancestor of SMG (MMG). Looking at MCG, one sees that the unfixed node strategy is not yet generalised. In that sense, the unfixed node strategy is specified to apply only for Wh-elements. Then, the transition to MCG involves generalisation of the unfixed strategy to apply to all elements that are parsed as unfixed nodes (subjects, objects, PPs, temporal expressions, adverbs). Lastly, PG derives from a system were proclitic environments are far fewer than the ones found in MCG or MMG. In MPG no general parsing trigger as a proclitic trigger is found, since the elements inducing proclisis cannot be generalised into one class. Hence, each of the elements must be encoded separately in the lexical entry for the clitic. The fact that proclitic environments were few in conjunction with the complexity of the lexical entry and the fact that only the enclitic trigger had a generalised flavor gave rise to a system where all proclitic triggers were dropped and only the enclitic trigger was retained.

Acknowledgements Open access funding provided by University of Gothenburg. The author is supported by grant 2014-39 from the Swedish Research Council, which funds the Centre for Linguistic Theory and Studies in Probability (CLASP) in the Department of Philosophy, Linguistics, and Theory of Science at the University of Gothenburg. A number of people are thanked for useful discussions and intuitions related to different parts of this paper: Ruth Kempson, Panayiotis Pappas, Miriam Bouzouita, Ronnie Cann, Eleni Gregoromichelaki, Christine Howes, Ioanna Sitaridou and Lutz Marten. All errors remain my own.

Open Access This article is licensed under a Creative Commons Attribution 4.0 International License, which permits use, sharing, adaptation, distribution and reproduction in any medium or format, as long as you give appropriate credit to the original author(s) and the source, provide a link to the Creative Commons licence, and indicate if changes were made. The images or other third party material in this article are included in the article's Creative Commons licence, unless indicated otherwise in a credit line to the material. If material is not included in the article's Creative Commons licence and your intended use is not permitted by statutory regulation or exceeds the permitted use, you will need to obtain permission directly from the copyright holder. To view a copy of this licence, visit http://creativecommons.org/licenses/by/4.0/.

\footnotetext{
29 An anonymous reviewer points out thar in Medieval Spanish, proclisis also spread to non-finite forms but then reverted back. This has been dubbed a "failed change" as the reviewer notes. There is no evidence for such a "failed change" for Medieval Greek.
} 


\section{References}

Blackburn, P., \& Meyer-Viol, W. (1994). Linguistics, logic and finite trees. Logic Journal of the IGPL, 2(1), 3-29.

Bouzouita, M. (2008). At the syntax-pragmatics interface: Clitics of Spanish. In R. Cooper \& R. Kempson (Eds.), Language in flux: Dialogue coordination, language variation, change and evolution (pp. 221263). London: College Publications.

Branigan, H. P., Pickering, M. J., \& McLean, J. F. (2005). Priming prepositional-phrase attachment during comprehension. Journal of Experimental Psychology: Learning, Memory, and Cognition, 31(3), 468.

Cann, R. (2010). Towards an account of the English auxiliary system. In E. Gregoromichelaki, R. Kempson, \& C. Howes (Eds.), The dynamics of lexical interfaces. Stanford: CSLI Publications.

Cann, R., Kempson, R., \& Marten, L. (2005). The dynamics of language. Oxford: Elsevier.

Chatzikyriakidis, S. (2009a). Clitics in Grecia Salentina Greek: A dynamic account. Lingua, 12, 1938-1968.

Chatzikyriakidis, S. (2009b). Clitic climbing in Grecia Salentina Greek: A dynamic account. Modern Greek Dialects and Linguistics Theory, 4(1), 280-304.

Chatzikyriakidis, S. (2010a). Clitics in four dialects of Modern Greek: A dynamic account. PhD thesis, University of London.

Chatzikyriakidis, S. (2010b). A dynamic account of clitic climbing: A first sketch. In E. Gregoromichelaki, R. Kempson, \& C. Howes (Eds.), The dynamics of lexical interfaces. Stanford: CSLI Publications.

Chatzikyriakidis, S. (2012). A dynamic account of clitic positioning in Cypriot Greek. Lingua, 122(6), 642-672.

Chatzikyriakidis, S., \& Kempson, R. (2011). Standard Modern and Pontic Greek person restrictions: A feature-free dynamic account. Journal of Greek Lingusitics, 11, 127-166.

Condoravd, C., \& Kiparsky, P. (2002). Clitics and clause structure. Journal of Greek Linguistics, 2(1), 1-39.

Crysmann, B. (2001). Phonological properties of Portuguese clitics. In 8th international conference on head-driven phrase structure grammar, pp. 3-5.

Garrod, S., \& Doherty, G. (1994). Conversation, co-ordination and convention: An empirical investigation of how groups establish linguistic conventions. Cognition, 53, 181-215.

Garrod, S., \& Pickering, M. J. (2004). Why is conversation so easy? Trends in Cognitive Sciences, 8(1), $8-11$.

Gregoromichelaki, E. (2006). Conditionals: A dynamic syntax account. PhD thesis, King's College London.

Grohmann, K., Papadopoulou, E., \& Themistocleous, C. (2017). Acquiring clitic placement in bilectal settings: Interactions between social factors. Frontiers in Communication, 2, 5.

Hatzidakis, G. (1897). Neugriechische studien. Zeitschrift für vergleichende Sprachforschung auf dem Gebiete der Indogermanischen Sprachen, 34(1. H), 80-143.

Healey, P., Purver, M., \& Howes, C. (2014). Divergence in dialogue. PLoS ONE, 9(6), e98598.

Horrocks, G. (1997). Greek: A history of the language and its speakers. Hoboken: Wiley.

Janse, M. (1993). La position des pronoms personnels enclitiques en grec néo-testamentaire à la lumière des dialectes néo-helléniques. Presses Universitaires de Nancy.

Katsoyannou, M. (1995). Le parler Gréco de Gallicianò (Italie): Description d'une Langue en Voie de Disparition. PhD thesis, Paris 7.

Kempson, R., \& Cann, R. (2008). Production pressures, syntactic change and the emergence of clitic pronouns. In R. Cooper \& R. Kempson (Eds.), Language in flux: Dialogue coordination, language variation, change and evolution (pp. 179-220). London: College Publications.

Kempson, R., \& Kiaer, J. (2010). Multiple long-distance scrambling: Syntax as reflections of processing. Journal of Linguistics, 46(01), 127-192.

Kempson, R., Meyer-Viol, W., \& Gabbay, D. (2001). Dynamic syntax: The flow of language understanding. Oxford: Blackwell.

Luis, A., Otoguro, R., Butt, M., \& King, T. H. (2004). Proclitic contexts in European Portuguese and their effect on clitic placement. In The proceedings of the LFG'04 conference, pp. 334-352.

Mussafia, A. (1886). A particular syntax of the Italian language of the first centuries. Florence: Le Monnier.

Pappas, P. A. (2004a). Medieval Greek weak object pronouns and analogical change: A response to Condoravdi \& Kiparsky (2001). Journal of Greek Linguistics, 5(1), 127-157.

Pappas, P. A. (2004b). Object clitic placement in the dialects of Medieval Greek. Modern Greek Dialects and Linguistics Theory, 2(1), 314-328.

Pappas, P. A. (2008). Object clitic placement in the history of Cypriot Greek. In Proceedings of Methods XIII. Frankfurt am Main: Peter Lang. 
Pappas, P. A. (2012). An empirical perspective on Cypriot clitics. Neoelliniki dialektologia [Modern Greek Dialectology], 6, 391-413.

Pappas, P. A. (2014). Exceptional clitic placement in Cypriot Greek: Results from an MET study. Journal of Greek Linguistics, 14(2), 190-211.

Pickering, M., \& Garrod, S. (2004). Toward a mechanistic psychology of dialogue. Behavioral and Brain Sciences, 27, 169-226.

Pickering, M. \& Garrod, S. (2005). Establishing and using routines during dialogue: Implications for psychology and linguistics. In Twenty-first century psycholinguistics: Four cornerstones (pp. 85-102).

Ralli, A. (2006). Syntactic and morphosyntactic phenomena in Modern Greek dialects: The state of the art. Journal of Greek Linguistics, 7(1), 121-159.

Revithiadou, A., \& Spyropoulos, V. (2008). Greek object clitic pronouns: A typological survey of their grammatical properties. STUF-Sprachtypologie und Universalienforschung, 61(1/2008), 39-53.

Rohlfs, G. (1977). Historical grammar of Italo-Greek dialects (Calabria, Salento). Munich: CH Beck.

Ruh, N., Cooper, R. P., \& Marescha, D. (2005). The time course of routine action. Austin: Cognitive Science Society Inc.

Sitaridou, I., \& Schreiber, L. F. (2015). Assessing sociolinguistic vitality: An attitudinal study of Romeyka (Rumca). In Talk given at the Center "Language, Variation, and Migration" University of Potsdam (Vol. 22, p. 2015).

Soltic, J. (2013). Clitic doubling in vernacular Medieval Greek. Transactions of the Philological Society, 111(3), 379-405.

Sperber, D., \& Wilson, D. (1995). Relevance: Communication and cognition (2nd ed.). Hoboken: Blackwell. Taylor, A. (2002). The distribution of object clitics in Koine Greek. Indo-European Perspectives, 43, 285315 .

Tobler, A. (1912). Besprechung von j. le coultre, de l'ordre des mots dans Chrétien de Troyes. In Vermischte Beiträge zur französischen Grammatik (Vol. 5, pp. 395-404). Leipzig: Hirzel.

Tsiplakou, S. (2017). Imperfect acquisition of a related variety? Residual clefting and what it reveals about (gradient) bilectalism. Frontiers in Communication, 2, 17.

Vejleskov, P. (2005). The position of the weak object pronoun in the Greek portulans and in the chronicle of the Turkish sultans. In Approaches to texts in early modern Greek=Anadromika Kai Prodromika (pp. 197-209). Oxford: Sub-Faculty of Modern Greek, University of Oxford.

Vogel, I., \& Nespor, I. (1997). Prosodic phonology. In M. Maiden \& M. Parry (Eds.), The dialects of Italy (pp. 58-67). New York: Routledge.

Publisher's Note Springer Nature remains neutral with regard to jurisdictional claims in published maps and institutional affiliations. 